\title{
OBJECT ORIENTED CLASSIFICATION AND FEATURE EXTRACTION FOR PARTS OF EAST DELHI USING HYBRID APPROACH
}

\author{
Pratyush Kumar ${ }^{1, *}$, Sudha Ravindranath ${ }^{2}$, K Ganesh Raj ${ }^{2}$ \\ ${ }^{1}$ School of Planning and Architecture, Delhi, India - praytush717bp16@spa.ac.in \\ ${ }^{2}$ RRSC - South, NRSC, Bengaluru India-ravisud4@gmail.com, ganeshraj@nrsc.gov.in
}

\section{Commission V, SS: Infrastructure and Development Planning}

KEY WORDS: Object Based Image Analysis (OBIA), High resolution satellite data, LU/LC Classification, Feature Extraction, Haralick textural methods, eCognition Developer

\begin{abstract}
:
Rapid urbanization of Indian cities requires a focused attention with respect to preparation of Master Plans of cities. Urban land use/land cover from very high resolution satellite data sets is an important input for the preparation of the master plans of the cities along with extraction of transportation network, infrastructure details etc. Conventional classifiers, which are pixel based do not yield reasonably accurate urban land use/land cover classification of very high resolution satellite data (usually merged images of Panchromatic \& Multispectral). Object Based Image Classification techniques are being used to generate urban land use maps with ease which is GIS compatible while using very high resolution satellite data sets. In this study, Object Based Image Analysis (OBIA) has been used to create broad level urban Land Use / Land Cover (LU/LC) map using high resolution ResourceSat-2 LISS-4 and Cartosat-1 pan-sharpened image on the study area covering parts of East Delhi City. Spectral indices, geometric parameters and statistical textural methods were used to create algorithms and rule sets for feature classification. A LU/LC map of the study area comprising of 4 major LU/LC classes with its main focus on separation of barren areas from built up areas has been attempted. The overall accuracy of the result obtained is estimated to be approximately $70 \%$
\end{abstract}

\section{INTRODUCTION}

Urban land use and land cover maps are a prerequisite for any analysis pertaining to the creation of Regional level plans, master plans or even zonal plans. The creation of LU/LC maps help in the analysis and in visual interpretation of the effects of human intervention on ground and also in visualizing it spatially on a map. This study aims to create LU/LC map of a part of east Delhi using object based image classification technique using a hybrid approach in which four broad LU/LC classes have been made. The main focus has been on the separation of barren features from urban built features.

Image classification deals with the making of different classes from a satellite image based on their characteristics. These characteristics are inherent into every pixel of the image in form of the intensity of the incident light onto each sensor. Based on

${ }^{*}$ Corresponding author the reflectance characteristics of the surface features present on earth the intensity of different bands of the spectra of light captured varies, thus making different features distinguishable in different bands.

Image classification methods can be mainly categorized into two types, (a) Pixel based and (b) Object based. In pixel-based image classification, the reflectance values of each pixel are used to determine the class of a pixel, this is done for the entire image. Pixel based image classification can further be of two types, Unsupervised and Supervised classification, in unsupervised classification, the computer itself analyses different properties of values in pixels in different bands and makes classes on its own. The user then has to check the classes for misclassification and has to name the classes accordingly. In a supervised classification, the user first provides the machine with training datasets in which different samples are taken for each class. The computer then reads the pixel values and reflectance characteristics for each band in the training samples and then uses machine learning to find more such pixels and classifies them as a class. 
In object-based image classification, the image is broken down or cut into small pieces also known as segments, which serves as building blocks for further analysis. This process is called as segmentation. Segmentation can be done using different algorithms, each catering to specific tasks.

An image object is a group of pixels in a map. Each object represents a definite space within a scene and objects can provide information about this space. The first image objects are typically produced by an initial segmentation.

The classification is done by reading and analyzing the characteristics of each image object of a specific class following which a rule set is developed to extract such objects. A step by step approach is undertaken using which classes are separated from the image in each step using a different rule set which applies for a specific class.

\subsection{Study Area}

The study area is a part of the administrative area of East Delhi, located in the state of Delhi, India. The area taken lies between 28.657499 to 28.581553 North latitudes and between 77.264781 to 77.390352 East longitudes.

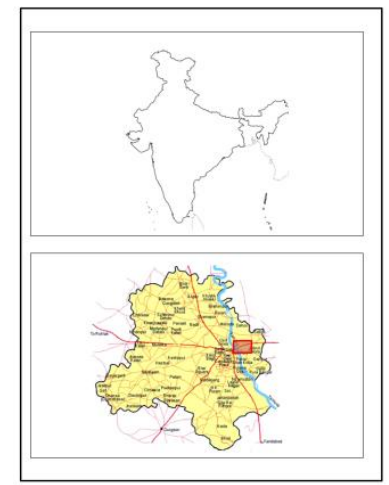

Figure 1 Study area

The most prominent features of the study area are the river Yamuna and Sanjay Lake, located in the locality of Patparganj, Major observable features of the study area are water bodies, urban built up, vegetation and barren lands.

\section{$1.2 \quad$ Related Work}

(Anderson, 1976) Studied the classification system for land use and land cover for use with remote sensing data, the study focused on defining a classification criteria and classification system for land use/ land cover maps.

(MA Frieda et al., 2002) studied the use of MODIS data for highly accurate classification of vegetation.

(Shridhar D. Jawak; Alvarinho J. Luis , 2013) studied the performances of six different pan sharpening algorithms and comprehensively evaluated the means to fuse pan and multi spectral data.

(Bhalerao, 1991) In his doctoral dissertation, integrated the regional and boundary information within the multi resolution framework. The study was able to extract boundary orientations from data with low signal-to-noise ratios.

(Li, 2017) In his doctoral dissertation extracted urban land use in an object-based image analysis setting by means of analyzing urban land cover obtained from very high resolution images.

(M.L. Comer ; E.J. Delp, 2002) Presented a new algorithm for segmentation of noisy or textured images using multi resolution Bayesian approach.

(McFeeters; Stuart K, 1996) proposed the use of Normalized Difference Water Index to identify non-urban surface water associated with wetlands. In this the formula for NDWI was given.

(Rouse Jr, 1973) in his report proposed the use of Normalized Difference Vegetation Index as a measure for accurately identifying vegetation from satellite imagery.

(Hay G.J., Castilla G., 2008) provides an early attempt at formally defining OBIA, they do a SWOT analysis of OBIA in order to strengthen it.

\section{Data USEd ANd Methodology}

\subsection{Data Used}

In this study, GIS software and remote sensing software, that is, ERDAS Imagine 2016, ArcGIS (version 10.5) and eCognition Developer (version $9.01 \mathrm{xs}$ ) were used. MS Office was also used for this study for data analysis and metadata review. The LISS-IV and Cartosat-1 data were used in this study. The satellite images obtained were georeferenced with WGS-84 datum and UTM zone 44 projection systems. The tables below give a brief description of the orbital characteristics and payload specifications of Cartosat-1. 


\begin{tabular}{|l|l|l|}
\hline $\begin{array}{l}\text { Sr. } \\
\text { No. }\end{array}$ & Orbit characteristic & Specifications \\
\hline 1 & Nominal altitude & $617.99 \mathrm{KM}$ \\
\hline 2 & Number of orbits per day & 16 \\
\hline 3 & Local time for equatorial crossing & $10: 30 \mathrm{AM}$ \\
\hline 4 & Orbital repeativity cycle & 126 days \\
\hline 5 & Orbital parameters & \\
& a) Semi major axis & $6996.12 \mathrm{KM}$ \\
& b) Eccentricity & 0.001 \\
& c) Inclination & 97.87 degree \\
\hline
\end{tabular}

Table 1 Orbital characteristic of Cartsat-1

\begin{tabular}{|c|c|c|}
\hline $\begin{array}{l}\text { Sr. } \\
\text { No }\end{array}$ & Parameter & $\begin{array}{l}\text { Specification Fore }(+26 \\
\text { deg) and Aft(-5 deg) }\end{array}$ \\
\hline 1 & $\begin{array}{l}\text { Spatial Resolution: } \\
\text { GIFOV (across track } \times \\
\text { along track) }\end{array}$ & $\begin{array}{l}2.22 \times 2.23 \mathrm{~m}(\text { Aft }) \\
2.5 \times 2.78 \mathrm{~m}(\text { Fore })\end{array}$ \\
\hline 2 & $\begin{array}{l}\text { Spectral Resolution: } \\
\text { a) No. of bands } \\
\text { b) Bandwidth }\end{array}$ & $\begin{array}{l}1 \text { Panchromatic } \\
500 \mathrm{~nm} \text { to } 850 \mathrm{~nm}\end{array}$ \\
\hline 3 & $\begin{array}{l}\text { Radiometric resolution } \\
\text { a) SNR } \\
\text { b) Quantization } \\
\text { c) Saturation } \\
\\
\text { radiance }\end{array}$ & $\begin{array}{l}345 \text { at saturation radiance } \\
10 \mathrm{bits} \\
55 \mathrm{mw} / \mathrm{cm} * \mathrm{~cm} / \mathrm{str} / \text { micron }\end{array}$ \\
\hline 4 & $\begin{array}{l}\text { CCD Parameters: } \\
\text { a) No. of } \\
\text { detectors/ } \\
\text { elements } \\
\text { b) Detector } \\
\text { element size } \\
\text { c) Odd even } \\
\text { spacing }\end{array}$ & $\begin{array}{l}1200 \text { per camera } \\
7 \times 7 \text { microns } \\
35 \text { microns staggered }\end{array}$ \\
\hline 5 & $\begin{array}{l}\text { Swath (stereo) } \\
\text { Fore + Aft combined } \\
\text { (mono) }\end{array}$ & $\begin{array}{l}30 \mathrm{KM} \\
26.855 \mathrm{KM}\end{array}$ \\
\hline 6 & $\begin{aligned} \text { Optics } & \\
\text { a) } & \text { No. of mirrors } \\
\text { b) } & \text { F-Number } \\
\text { c) } & \text { Focal length } \\
& \text { (effective) } \\
\text { d) } & \begin{array}{l}\text { Field of view } \\
\text { (degrees) }\end{array}\end{aligned}$ & $\begin{array}{l}3 \\
F / 4.5 \\
1980 \\
+/-1.08\end{array}$ \\
\hline 7 & $\begin{array}{l}\text { Nominal } \mathrm{B} / \mathrm{H} \text { ratio for } \\
\text { stereo }\end{array}$ & 0.62 \\
\hline 8 & Integration time $(\mathrm{ms})$ & 0.336 \\
\hline
\end{tabular}

Table 2 Payload specifications of Cartosat-1

eCognition developer software is a powerful development setting or environment for OBIA (object-based image analysis). The object-based approach facilitates analysis of all common data sources, such as medium to high resolution satellite data, high to very high resolution aerial photography, lidar, radar and even hyper-spectral data. The user can choose from a variety of segmentation algorithms such as multiresolution segmentation, quad tree or chessboard. The scope of classification algorithms ranges from sample-based nearest neighbor, fuzzy logic membership function or specialized context-driven analysis.

\subsection{Methodology}

The process of feature extraction is mainly divided into three parts: (a) Image preprocessing, (b) semi automated object oriented fuzzy classification and (c) extraction of features to GIS vector formats.

In the image pre-processing, high resolution panchromatic and multispectral satellite imagery of the study area were obtained and were subjected to georeferencing and orthorectification, followed by which they were mosaicked. The mosaicked product for both the Cartosat-1 panchromatic and LISS-IV multispectral data were then fused together with the help of Bovey transformation and Bilinear interpolation method. Details of methodology is given in figure below

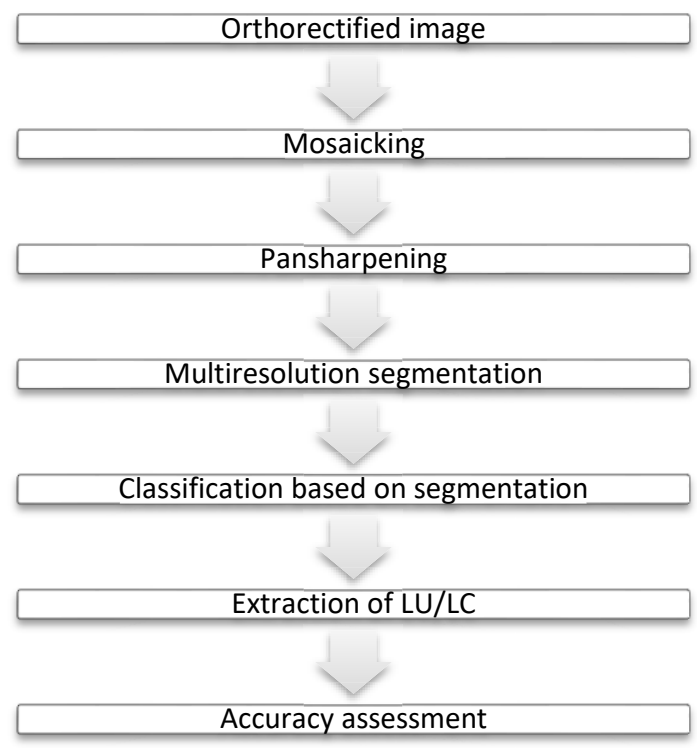

Figure 2 Detail of Methodology

In this study, the classification was conducted by fuzzy logic. The segmentation was tried out using different combinations of shape and compactness parameters at varying resolutions. This type of image segmentation technique is called as multi resolution segmentation. It is a procedure which allows segmentation of image into a network of homogeneous image regions at any chosen resolution (Pandey, 2004) (Gamba, Paolo ; Dell'Acqua, Fabio., 2007) These image objects obtained represent image information in abstract form, carrying information and serving as building blocks for ensuing classification. 
2.2.1 Multi resolution segmentation: For the multiresolution segmentation and classification, the rule based rubrics were found out using different user defined arithmetic layers, such as NDVI (Normalized difference vegetation index), LWM (Land water mask), and Green Ratio, were used, as given in the table below.

\begin{tabular}{|l|l|c|}
\hline $\begin{array}{l}\text { Sr. } \\
\text { No. }\end{array}$ & $\begin{array}{l}\text { Arithmetic } \\
\text { Layer }\end{array}$ & Formula \\
\hline 1 & NDVI & NDVI $=\frac{\text { NIR }- \text { Red }}{\text { NIR }+ \text { Red }}$ \\
\hline 2 & LWM & $L W M=\frac{\text { NIR }}{\text { Green }+0.0001} * 100$ \\
\hline 3 & Green Ratio & G Ratio $=\frac{\text { Green }}{\text { NIR }+ \text { Red }+ \text { Green }}$ \\
\hline
\end{tabular}

Table 3 User defined arithmetic layers

Apart from the above, band values were also used to differentiate diverse classes and ground features in the satellite images.

In order to separate the built-up features from barren lands, statistical textural methods were used, namely GLCM and GLDV to separate the features based upon the textural characteristics they carried. GLCM: Grey Level Co-occurrence Matrix is a tabulation of how often different combinations of pixel gray levels could occur in an image. Its goal is to assign an unknown sample image to one of a set of known texture classes. Textural features can be scalar numbers, discrete histograms or empirical distributions. They characterize the textural properties of the images, such as spatial structure, contrast, roughness, orientation, etc. and have certain correlation with the desired output. (Haralick RM, 1973). GLDV: Grey Level Difference Vector is a statistical texture method which extracts a set of statistical parameters like inertia, correlation, etc. from given image. "GLDV estimates the probability density function for differences taken between image function values at locations spaced some pixels apart and at an angle" (Richardson, Kim; Nahid Khazenie, 1992)

After multilevel resolution at a scale of 50 with compactness as 0.5 and shape factor as 0.1 , the image objects obtained were classified as given below:

2.2.2 Feature Extraction: First the vegetation features were extracted based on their NDVI and brightness values, followed by which water features were extracted using the NDVI, LWM, Mean NIR, Brightness and Maximum difference values along with the area parameter of image object. This gave some misclassified image objects as water which were removed on the basis of their GLCM Homogeneity and Green Ratio values. From the remaining unclassified objects water boundaries were extracted using contextual/relational information of their relative border to already classified water body and their areas. The entire water bodies and water boundaries were then merged and extracted in GIS vector formats.

After extraction of water, image objects containing built-up were extracted on the basis of their NDVI, LWM, Brightness, Mean
NIR and GLCM homogeneity. Shadows of built up areas were also considered using their relative boundary values to image objects classified as built-up already. Barren land also was misclassified under this, the only way to separate the barren land from urban built-up was on the basis of the texture that image objects of the two classes had. In order to separate the barren land features misclassified as built up, from both the classified built-up objects and the unclassified objects, barren land was extracted using GLCM Homogeneity (all direction), GLCM homogeneity quick 8/11 (all direction), G Ratio, GLCM entropy and GLDV $2^{\text {nd }}$ angular momentum(all direction).

The flowchart below shows the process of classification followed to create four broad LU/LC classes of the study area.

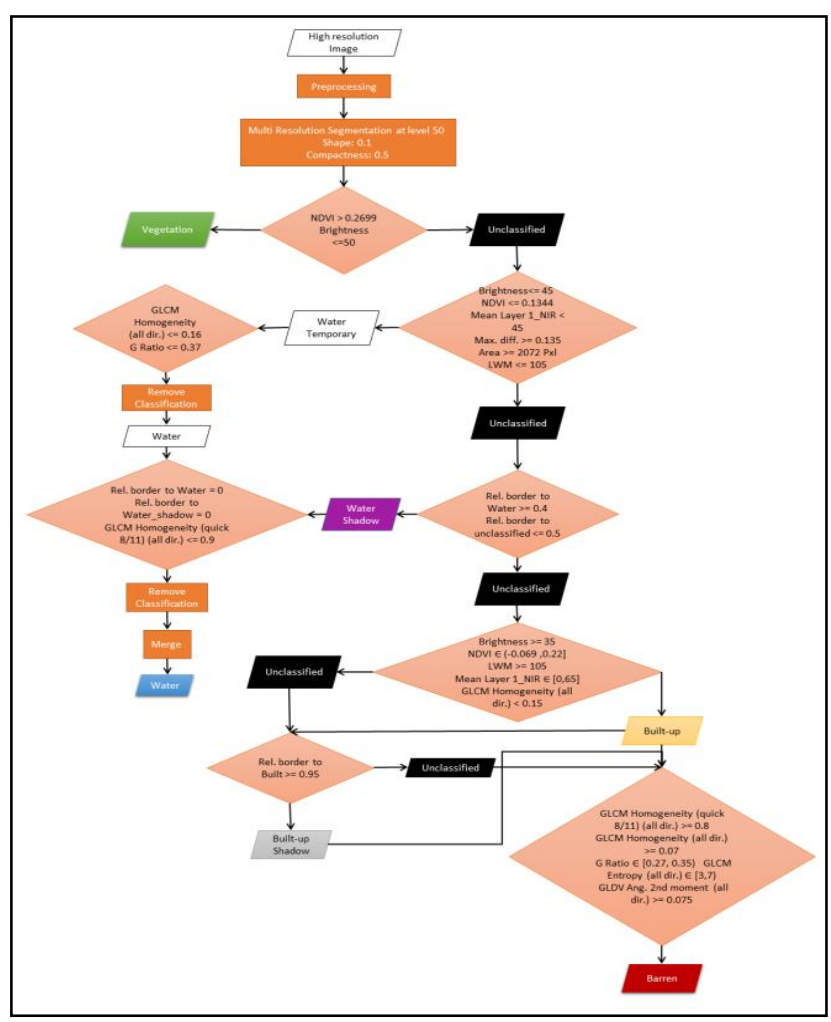

Figure 3 Flowchart of process followed for classification 
2.2.3 Accuracy Assessment: After the multiresolution segmentation, accuracy check was done on the obtained segmented image in three stages. First, a grid of $300 \mathrm{~m} \times 300 \mathrm{~m}$ was generated and overlaid onto the segmented image as shown in the figure below.

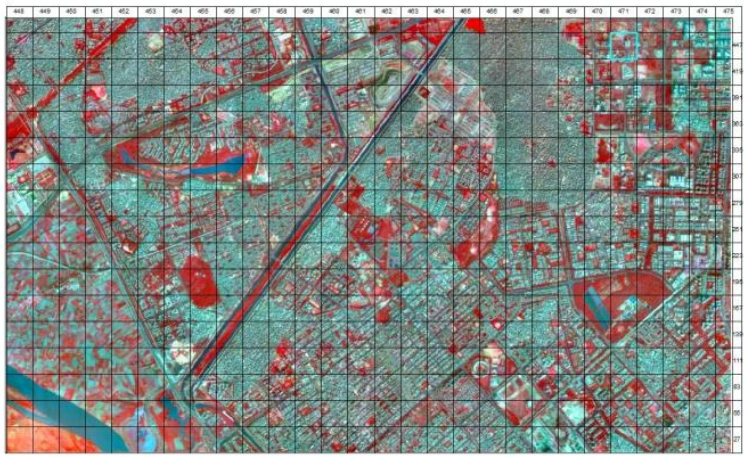

Figure 4 Grid overlaid over the reference image

After plotting the grid on the map, 45 elements within the grid were selected at random using the RAND() function in MS Excel. Within each of the grid, 5 points were chosen at random for every class in the segmented image, i.e., a total of 20 random points in each element. The figure below shows the random points in a specific element of the grid.

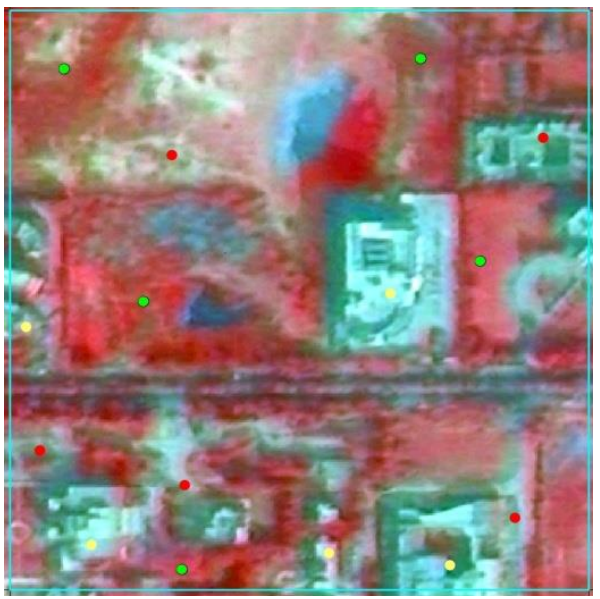

Figure 5 Points taken at random for accuracy check

These points were then compared with the original satellite image for accuracy evaluation and conflicting points were recorded.

\section{RESULTS AND DISCUSSION}

\subsection{Multi resolution segmentation}

The pansharpened images were subjected to segmentation using eCognition Developer software. In context of creation of LU/LC map of study area, the segmentation was carried out to adjust scale parameter, shape factor and compactness. These parameters were adjusted to obtain image objects with homogeneous region with defined edge of objects of concern. Once these parameters are adjusted to satisfy the above criteria, the image objects obtained can be further used for fuzzy rule based classification and extraction.

By taking a scale parameter of 50, shape factor of 0.1 and compactness of 0.5 , the image objects obtained were of homogenous pattern. Water bodies and their boundaries could be taken separately, built-ups and barren lands and similarly vegetation and agricultural lands, all were obtained in separate image objects, which could then be classified.

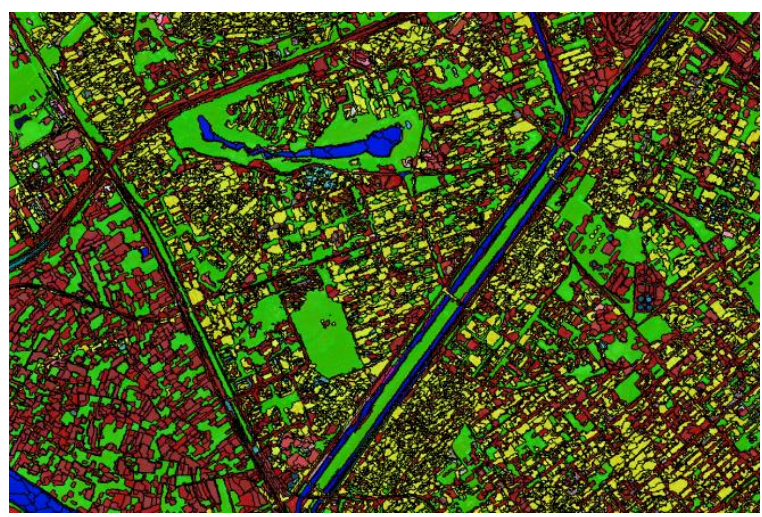

Figure 6 Image objects obtained after classification

\subsection{Accuracy measurement}

In this study, the detection accuracy of the rule set used was checked. It was calculated in terms of the percentage of the number of objects correctly classified to the total number of objects in the sample space checked for each class.

After the assessment vegetation class was detected most accurately with $83 \%$ accuracy, water with an accuracy of $72 \%$, built-up with accuracy of $66 \%$ and barren class with an accuracy of $57 \%$.

\section{Conclusion}

The goal of this study was to classify and make Land Use/Land Cover map from high resolution satellite imagery of ResourceSat2 LISS-4 and Cartosat-1 pan-sharpened images using a semiautomated approach. An urban image subset of a part of East Delhi city was analyzed using image segmentation and object based image classification, based on rule sets defined to extract each class of land cover, resulting in accurate land cover maps of the study area.

The satellite image used was not subjected to any normalization prior to the object base image analysis, so the rule set obtained cannot be used for images from other satellites, however the methodology would remain same for all images. Object-oriented 
classification allows automated classification with very high accuracy, with rule sets based on the contexts and textural patterns of the image objects obtained. An overall accuracy of $70 \%$ was obtained using the methodology adopted for the study.

Using some normalization for the image dataset obtained would make the rule sets obtained from this study more versatile to use with data from varying satellites and sensors, there is a scope on the improvement of accuracy of the features extracted.

\section{ACKNowledgements}

The authors would like to thank the reviewers for their insightful comments and suggestions. We extend our sincere thanks to the technical as well as non-technical staff of Regional Remote Sensing Center- South, Bengaluru for providing moral support during the course of our work.

\section{REFERENCES}

Anderson, J. R. (1976). A Land Use and Land Cover Classification System for Use with Remote Sensor Data. Geological Survey professional paper .

Attarzadeh, R. and Momeni, M. (2012): Object-Based Building Extraction from High Resolution Satellite Imagery, Int. Arch. Photogramm. Remote Sens. Spatial Inf. Sci., XXXIX-B4, 57-60, https://doi.org/10.5194/isprsarchives-XXXIX-B4-57-2012.

Bhalerao, A. \&. (1991). Multiresolution image segmentation. Doctoral dissertation, University of Warwick .

Gamba, Paolo ; Dell'Acqua, Fabio. (2007). Spectral Resolution in the Context of Very High Resolution Urban Remote Sensing. Urban Remote Sensing, 377-391.

Haralick RM, S. K. (1973). Textural features for image classification. IEEE Transactions on Systems Man and Cybernetics , SMC3(6), 610 - 621.

Li, M. (2017). Urban land use extraction from very high resoliution remote sensing data. Doctoral Dissertation. Netherlands: University of Twente.

M.A Friedl; D.K McIver; J.C.F Hodges; X.Y Zhang; D Muchoney; A.H Strahler; C.E Woodcock; S Gopal; A Schneider; A Cooper; A Baccini; F Gao; C Schaaf. (2002). Global land cover mapping from MODIS: algorithms and early results. Remote Sensing of Environment , 83 (1-2), 287-302.
M.L. Comer ; E.J. Delp. (2002). Multiresolution image segmentation. International Conference on Acoustics, Speech, and Signal Processing .

McFeeters; Stuart K. (1996). The use of the Normalized Difference Water Index (NDWI) in the delineation of open water features. International journal of remote sensing , 1425-1432.

M Labib, Angela Harris. (2018) The potentials of Sentinel-2 and LandSat- 8 data in green infrastructure extraction, using object based image analysis (OBIA) method. European Journal of Remote Sensing 51:1, pages 231-240.

Pandey, A. (2004). Automatic Urban Road Extraction using airborne laser scanning- aitimetry and high resolution satellite data. Tweente: Enschede: ITC.

Richardson, Kim; Nahid Khazenie. (1992). Comparision of Texture Analysis Techniques in Both Frequency and Spatial Domains for cloud Feature Extraction. Boulder: NAVAL RESEARCH LAB MONTEREY CA.

Rouse Jr, J. W. (1973). Monitoring the vernal advancement and retrogradation (green wave effect) of natural vegetation. Texas: TEXAS A\&M UNIVERSITY.

Shridhar D. Jawak; Alvarinho J. Luis . (2013). A Comprehensive Evaluation of PAN-Sharpening. Advances in Remote Sensing, 332-344.

Shrivastava, Neeti \& Rai, Praveen. (2015). An object based building extraction method and classification using high resolution remote sensing data. Forum geografic. XIV. 14-21. 10.5775/fg.2067-4635.2015.045.i.

Yunqing Jing, Fei Zhang, Xiaoping Wang. (2018). Monitoring dynamics and driving forces of lake changes in different seasons in Xinjiang using multi-source remote sensing. European Journal of Remote Sensing 51:1, pages 150-165. 